\title{
Adoção de Métodos Científicos como Componente Metodológica e sua Explicitação nas Dissertações Publicizadas entre 2010 e 2014 de um Programa de Pós-Graduação em Administração
}

\author{
Adoption of Scientific Methods as a Methodological \\ Component and its Explicitation in the Dissertations of a \\ Graduate Program in Administration Between 2010 and 2014
}

\section{Ruy Tadeu Mambrini Ribas}

Mestrando em Administração Universitária. Universidade Federal de Santa Catarina - UFSC. Florianópolis, SC. Brasil. E-mail: ruy.ribas@ufsc.br

Luís Carlos Cancellier de Olivo

Doutor em Direito. Professor de Direito Público e Administrativo no Programa de Pós-Graduaçao em Administração Universitária da Universidade Federal de Santa Catarina - UFSC. Florianópolis, SC. Brasil. E-mail: luis.cancellier@ufsc.br

\section{Resumo}

O presente estudo procura ressaltar a importância da adoção de determinadas componentes metodológicas para que uma produção intelectual possa se pretender verdadeiramente científica. Assim sendo, discorre sobre as principais "escolas" de metodologia - a saber, indutiva, dedutiva, hipotético-dedutiva e dialética para, em seguida, buscar nas dissertações de mestrado de um Programa de Pós-Graduação em Administração menções - por parte dos autores - da adoção de um dos referidos métodos como paradigma para a condução da exposição acadêmica que realizaram. O estudo não analisa a adequação da escolha metodológica nem a correta aplicação dos pressupostos de cada método, mas sim, a ostensividade das escolhas feitas ou não. Trata-se de pesquisa de natureza descritiva, quanto aos fins, e classificada, quanto aos meios, como um estudo de caso. Analisadas todas as dissertações apresentadas entre os anos de 2010 e 2014, percebeu-se baixa taxa de aderência a uma das metodologias por parte dos autores que, se realizaram opções metodológicas, não as explicitaram ao longo de seus textos.

Palavras-chave: Metodologia Científica. Método Indutivo. Método Dedutivo. Método Hipotéticodedutivo. Método Dialético.

\section{Abstract}

This study seeks to highlight the importance of adopting certain methodological components to make an intellectual production truly scientific. Therefore, it briefly discusses the main "schools" of methodology namely, inductive, deductive, hypothetical-deductive and dialectical - to then seek the thesis of one Graduate Program in Administration for statements - by the authors - about the adoption of one of these methods as paradigm for conducting the academic exhibition held. The research does not review the adequacy of the methodological choices nor the correct application of the methodos, but only the statement of methodological option or choice itself. It is a descriptive research, as to the purposes, and classified as to the means, as a case study. Analyzed all essays submitted between the years 2010 and 2014 it was possible to perceive the low adherence rate of the theses to specifically one of the scientific methods. In other words, the authors did not make explicit throughout their work if they defined (and thus followed) any methodological paths whatsoever.

Keywords: Scientific Methodology. Inductive Method. Deductive Method. Hypothetical Method. Dialectical Method. 


\section{INTRODUÇÃO}

O presente artigo procura investigar aspectos metodológicos das dissertações tornadas públicas, portanto aprovadas, por um Programa de Pós-graduação em Administração ${ }^{1}$ entre os anos de 2010 e 2014.

Dentre os vários aspectos metodológicos que poderiam ser analisados e explorados, esta produção focar-se-á em apenas um deles, no entanto, por parecer este de especial relevância em qualquer produção que se pretenda científica. O objeto do estudo em tela será o dos métodos de raciocínio, ou técnicas de raciocínio, a depender do autor utilizado para empréstimo dos conceitos.

A pesquisa terá, como se pode depreender do alvo supramencionado, sua população nas dissertações defendidas para obtenção do grau de mestre no programa referido. Foram consideradas para o estudo todas as obras datadas entre 2010 e 2014, sem outros recortes arbitrários ou temáticos.

$\mathrm{O}$ que se quer com o estudo é verificar a que linha metológica, ou a que técnica de raciocínio, as dissertações enquadradas nos critérios acima declaram se filiar. Dessa forma, esse é o objetivo geral do presente trabalho que terá como objetivos "intermediários" ou específicos descrever, mesmo que brevemente, os principais métodos científicos - a saber, indutivo, dedutivo, hipotético-dedutivo e dialético - e analisar a presença da declaração da opção por um deles ao longo das produções dos agora mestres pelo Programa em questão.

Importante ressaltar, no entanto, que não se faz qualquer análise de pertinência da opção por um dos métodos nem da correta "aplicação" quando da declaração da escolha por um ou outro deles. A pesquisa, nesse aspecto, é objetiva e não analisa o mérito mas, de certa maneira, apenas o aspecto "formal" das escolhas.

\section{Fundamentação TeÓRICA}

Inicialmente, cumpre definir o conceito geral de método científico e sua instrumentalidade na produção

\footnotetext{
1 Por questões éticas não se realizará menção direta ao nome do Programa e a sua Instituição-sede, sendo ele referido sempre de forma genérica com a finalidade de não identificá-lo, já que não há intenção, neste artigo, de se fazer julgamento dos méritos do mencionado programa, mas apenas destacar o estado, nele, de uma questão emergente - a fragilidade em aspectos metodológicos - na produção científica da Área em que se encontra.
}

de obras pelo intelecto humano, para, então, passar-se em revista dos métodos científicos em espécie, conforme classificados pelos estudiosos da matéria. Como se verá, o percurso lógico realizado nas pesquisas feitas sob a filiação de cada um dos métodos, é a marca distintiva entre um e outro no catálogo de possibilidades que se coloca ao pesquisador, cientista. Destas conceituações, divisões e distinções entre métodos científicos que se ocupa esta seção.

\subsection{Métodos Científicos (ou Métodos de Raciocínio)}

A produção científica diferencia-se de outras obras pela utilização de determinado ferramental específico, o método científico. Em simultâneo, nem todo o estudo ou ramo de estudo que tenha o cuidado de empregar um método científico será necessariamente o que se pode chamar de ciência (LAKATOS; MARCONI, 2007).

Em outras palavras, Lakatos e Marconi (2007, p. 44, grifos dos autores) afirmam ser possível concluir "[...] que a utilização de métodos científicos não é da alçada exclusiva da ciência, mas não há ciência sem o emprego de métodos científicos".

É que para que certo conhecimento (ou produção do intelecto humano) seja considerado científico, ciência, portanto, faz-se necessário identificar o percurso relizado, o caminho que permitiu chegar até tal conhecimento ou produto. As operações mentais feitas pelo autor precisam ser perceptíveis por aquele que aprecia sua obra justamente para que se possa verificar o "processo" e seu resultado final (GIL, 2008).

Em analogia é como a necessidade de vestígios, sinais em uma trilha, marcas de passadas, para que se identifique o ponto de partida no qual um indivíduo iniciou sua jornada e de que forma ao final chegou, por que caminhos e de que maneira percorreu a estrada.

Ao longo da história, inúmeros foram os pensadores desejosos de definir ou estabelecer um método universal, aplicável em todo caso e em qualquer ramo do conhecimento. Malgrado nobre objetivo, empreendimento impossível de ser realizado. Já há bom tempo consensua-se falar, com propriedade, numa diversidade de métodos possíveis, cada um guardando maior ou menor pertinência com certos objetos a serem investigados; mais ou menos proximidade com as 
proposições a serem descobertas e instrumentalidade diante destas.

Diante da variedade de métodos que podem ser utilizados no percurso científico e na medida em que cada um deles possui traços distintos - quando não verdadeiramente opostos - e aplicabilidades próprias, é conveniente classificá-los, ordená-los com base em certos critérios. A sistematização dos chamados métodos científicos seguramente facilita o trabalho do pesquisador quando se encontra diante da necessidade de fazer escolhas, opções metodológicas pertinentes ao seu estudo.

Aqui, novamente, os estudiosos da metodologia iniciam um sem fim de divergências. Cada autor tem seus critérios preferidos para subdividir ou agrupar técnicas ou métodos. Alguns chegam a divergir sobre o que é verdadeiramente um método ou meramente uma técnica.

Para os fins deste estudo serão considerados os "métodos que proporcionam as bases lógicas da investigação", conforme classificação proposta por Gil (2008, p. 9).

Em que pese a discordância de parte da literatura que entende indução e dedução, por exemplo, como itens presentes no rol da categoria de "técnicas de abordagem, de pensamento e de raciocínio" pois "[...] não são métodos científicos propriamente ditos. São mais adequadamente caracterizados como formas de abordagem de um tema, formas de raciocínio ou de argumentação [...]" (CERVO; BERVIAN; SILVA, 2006, p. 43) parece mais acertada a proposição de Gil.

Explica-se: Marconi e Lakatos (2007) esclarecem, calcando posicionamento em excertos de uma série de outros autores, o conceito de método. Das seleções que eles fazem, importante é a de Trujillo (apud MARCONI; LAKATOS, 2007, p. 44):

Método é a forma de proceder ao longo de um caminho. Na ciência os métodos contituem os intrumentos básicos que ordenam de início o pensamento em sistemas, traçam de modo ordenado a forma de proceder do cientista ao longo de um percurso para alcançar um objetivo.

Marconi e Lakatos (2007, p. 46) resumem o método como um conjunto de atividades "sistemáticas e racionais" que permitem, "com maior segurança e economia", alcançar o objetivo de conhecimento válidos e verdadeiros; para as autoras, o método traça "[...] o caminho a ser seguido, detectando erros e auxiliando as decisões do cientista".

$\mathrm{O}$ que parece um entendimento mais alinhado com o exposto até esse ponto e com aquilo que Gil (2008) leciona acerca "[...] dos métodos que proporcionam as bases lógicas da investigação". Para o autor,

Estes métodos esclarecem acerca dos procedimentos lógicos que deverão ser seguidos no processo de investigação científica dos fatos da natureza e da sociedade. São, pois, métodos desenvolvidos a partir de elevado grau de abstração, que possibilitam ao pesquisador decidir acerca do alcance de sua investigação, das regras de explicação dos fatos e da validade de suas generalizações. (GIL, 2008, p. 9)

\section{E continua:}

Podem ser incluídos neste grupo os métodos: dedutivo, indutivo, hipotético-dedutivo, dialético e fenomenológico. Cada um deles vincula-se a uma das correntes filosóficas que se propõem a explicar como se processa o conhecimento da realidade. $\mathrm{O}$ método dedutivo relaciona-se ao racionalismo, o indutivo ao empirismo, o hipotético-dedutivo ao neopositivismo, o dialético ao materialismo dialético e o fenomenológico, naturalmente à fenomenologia. (GIL, 2008, p. 9)

O intróito é extenso como também são os trechos colacionados, mas parece pertinente a medida para que sejam dirimidas questões terminológicas. Para os efeitos deste trabalho, "metodologia" é o que já se expôs e são aquelas acima as suas subcategorias.

Ainda, sobre a modalidade fenomenológica não se alongará mais adiante, pois se trata de modal metodológico de peculiaridade muito própria e de uso também bastante específico. Basta considerar que para a fenomenologia tem como seu objeto de conhecimento não o sujeito nem o mundo, "mas o mundo enquanto é vivido pelo sujeito". A relidade, portanto, não é compreendida como algo objetivo e, assim sendo, existe de forma plural - as realidades existem em tantos números quanto forem as interpretações $e$ comunicações de uma realidade (GIL, 2008, p. 14-15).

Justamente pela "[...] inexistência de planejamento rígido e da não-utilização de técnicas estruturadas [...]" típicas da pesquisa fenomenológica não há como 
se afastar "[...] o peso da subjetividade na interpretação dos dados [...]" e, assim, os riscos de distorçoes ou deformações da realidade pela consciência do pesquisador que segue sem aquelas "[...] definições e conceitos, como ocorre nas pesquisas desenvolvidas segundo a abordagem positivista." (GIL, 2008, p. 15).

Sendo a fenomenologia tópico, pelo exposto, bastante sensivel e merecedor de tantas outras linhas de ressalvas e considerações, e pela própria limiariedade em que caminha sobre o campo científico e o não científico - por romper com preceitos positivistas, objetivos, e científicos para muitos, portanto - as considerações teóricas e a posterior análise serão feitas respeitando os outros quatro métodos elencados por Gil (2008), a repisar, indutivo, dedutivo, hipotético-dedutivo e dialético.

\subsection{Método Indutivo}

O método indutivo fundamenta-se na observação de um objeto ou fenômeno específico para que se alcancem, partindo dele, conclusões gerais ou universais. É que quando se parte da observação consistente do específico, proposições gerais ganham força e plausibilidade (MEZZAROBA; MONTEIRO, 2004).

A indução, portanto, é um processo mental que parte de dados particulares e, na medida em que estes vão sendo "suficientemente constatados", permite-se inferir uma verdade mais ampla que aquela contida inicialmente nas partes examinadas. É um procedimento generalizador que tem como objetivo chegar a conclusões de conteúdo muito mais amplo que as próprias premissas que foram utilizadas de alicerce (MARCONI; LAKATOS, 2007, p. 53).

Ora, justamente pelo fato de as conclusões obtidas extrapolarem a verdade contida nas premissas inicialmente consideradas, tornam-se resultados plausíveis, possíveis, prováveis, "[...] mas não dotados daquele grau de rigor que a Lógica chama de conclusões necessárias." (MEZZAROBA; MONTEIRO, 2004, p. 63).

Cervo e Bervian referenciados por Lakatos e Marconi (2007, p. 53) lançam palavras esclarecedoras:

[...] pode-se afirmar que as premissas de um argumento indutivo correto sustentam ou atribuem certa verossimilhança a sua conclusão. Assim, quando as premissãs são verdadeiras, o melhor que se pode dizer é que sua conclusão é provavelmente verdadeira.

Cervo e Bervian complementam em outra obra, agora em conjunto com Silva (2007, p. 44-45) explicando que:

O argumento indutivo baseia-se na generalização de propriedades comuns a certo número de casos até agora observados e a todas as ocorrências de fatos similares que poderão ser verificados no futuro. $\mathrm{O}$ grau de confirmação dos enunciados traduzidos depende das evidências ocorrentes

E asseveram mais adiante que:

Não é, entretanto, a repetição da experiencia nem o grande número de observações ou experiências que conduzem à conclusão. Basta uma experiência para autorizar a conclusão do fenômeno para a lei. Se a experiência for repetida, não é por desconfiar do raciocínio, mas pelo temor de haver engano quanto aos resultados da experiência. Basicamente, a repetição é uma simples verificação da primeira prova, e não uma condição necessária da indução.

Como método científico a indução representa uma técnica de limitações e oportunidades próprias. Desde o "Novum organum", de Francis Bacon, o método indutivo "[...] passou a ser visto como o método por excelência das ciências naturais" (GIL, 2008, p. 11).

Assim é, pois, o método indutivo "[...] é uma forma de organizar o raciocínio da pesquisa, que é pressuposto básico para a existência de qualquer tipo de Ciência experimental [...]", pois sem esse artifício a própria “[...] concepção de Ciência estaria limitada a um conhecimento sem possibilidade de comprovação ou verificação" (MEZZAROBA; MONTEIRO, 2004, p. 64-65).

Fica fácil compreender a razão dos excertos apresentados. Imagine-se um pesquisador que descobre uma substância capaz de destruir ou regenerar determinado tipo de célula. Pela indução pode-se prosseguir no estudo ao ponto de demonstrar-se que aquele princípio químico atua em qualquer ou em diversas situações, com constância, consistência. Nessa situação ter-se-ia, por exemplo, a cura do câncer ou uma revolução no mercado de fármacos. Cabe lembrar que a penicilina é um dos frutos do método indutivo (MEZZAROBA; MONTEIRO, 2004). 
Vistas as capacidades do método indutivo, cabe apontar que ele é alvo de uma série de críticas e questionamentos e, a bem da verdade, é mister concordar que, realmente, o pesquisador que deste método se servir sem cautelas apropriadas ou em situações inadequadas flerta perigosamente com a possibilidade de incorrer em inconsistências graves.

É que o método, a despeito de seus méritos, não se aplica com a mesma "facilidade" em determinados campos ou estudos das ciências humanas ou sociais, por exemplo. Em uma indução ingênua bastaria identificar uma aula de um professor - ou um semestre, se queira - para afirmar a qualidade do magistério daquele docente. Ou ainda, verificar ilegalidade em um ato administrativo específico para concluir que apenas desta forma move-se o poder público, plausivelmente maculado em todos os seus atos, pela indução realizada.

Os apontamentos negativos ao método indutivo perpassam uma série de argumentos como os da possibilidade de amostras insuficientes ou tendenciosas, do equívoco, na indução, entre correlação e causalidade, problemas lógicos, envolvendo a própria lógica indutiva $e$ assim em diante.

Pela natureza do escrito não haverá aprofundamento neste ponto específico. A intenção da presente seção é a de caracterizar o método indutivo como uma técnica que permite partir do conhecido ao desconhecido com alguma dose de plausibilidade e que o método fundamenta-se no percorrer um caminho que "[...] vai do especial ao mais geral, dos indivíduos às espécies, das espécies ao gênero, dos fatos às leis ou das leis especiais às leis mais gerais" (MARCONI; LAKATOS, 2007, p. 53).

\subsection{Método Dedutivo}

O método dedutivo surge como sistema alternativo $e$, verdadeiramente, inverso ao da lógica indutiva. Aqui o processo mental, ou seja, o caminho lógico percorrido parte de "[...] príncipios reconhecidos como verdadeiros e indiscutíveis e possibilita chegar a conclusões de maneira puramente formal, isto é, em virtude unicamente de sua lógica" (GIL, 2008, p. 9).

É o método usualmente escolhido por autores (e, consequentemente, estudos) de cunho mais formalista. Inicialmente são explicitados os argumentos tomados como "verdadeiros e inquestionáveis" para, partindo dele, buscar conclusões formais. Dizem-se formais os resultados, pois decorrentes de operações lógicas realizadas em cima daquelas premissas inicialmente estipuladas (MEZZAROBA; MONTEIRO, 2004, p. 65).

Em outros termos, "A dedução é a argumentação que torna explícitas verdades particulares contidas em verdades universais". Começa-se nos antecedentes outro termo para as premissas ou argumentos iniciais - buscando chegar-se ao consequente, "[...] uma verdade particular ou menos geral contida implicitamente no primeiro" (CERVO; BERVIAN; SILVA, 2006, p. 46).

Cervo, Bervian e Silva (2006), como advertido em seção anterior do presente texto, não compreendem também a dedução como uma metodologia, mas sim como uma técnica argumentativa. A despeito dessa divergência boa é a explicação dos autores quando dizem que "A técnica dessa argumentação consiste em construir estruturas lógicas, por meio do relacionamento entre antecedente e consequente, entre hipótese e tese, entre premissas e conclusão" (CERVO, BERVIAN; SILVA, 2006, p. 46).

Em seguida, os autores complementam ainda com citação que, embora extensa, merece colagem pela clareza e boa síntese do que se vem expondo:

O cerne da dedução é a relação lógica que se estabelece entre proposições, dependendo seu vigor do fato de a conclusão ser sempre verdadeira, desde que as premissas também o sejam. Assim, admitindo-se as premissas, deve-se admitir também a conclusão; isso porque toda a afirmação ou conteúdo factual da conclusão já estava, pelo menos implicitamente, nas premissas. (CERVO; BERVIAN; SILVA, 2006, p. 46)

Então, como se percebe, o método dedutivo também apresenta oportunidades e ameaças ao pesquisador. Enquanto o raciocínio indutivo procura ampliar o alcance dos conhecimentos, o dedutivo explicitar um conteúdo das premissas (MARCONI; LAKATOS, 2007).

Mezzaroba e Monteiro (2004, p. 65) lecionam bem quando apontam que:

Se, por um lado, o método dedutivo possibilita levar o investigador do conhecido para o desconhecido com uma margem pequena de erro, por outro, esse mesmo método tem seu alcance bastante limitado, já que sua conclusão 
não pode em hipótese alguma ultrapassar o conteúdo enunciado nas premissas.

Em suma, se a indução aumenta o conteúdo das premissas, sacrificando, de alguma forma, a precisão do resultado - que, como visto não pode ser tomado como conclusão absoluta, mas apenas dotada de alguma medida, maior ou menor, de plausibilidade - a dedução, no intuito de assegurar a "certeza" do produto da pesquisa, por sua vez, prejudica a medida de "ampliação do conteúdo" (MARCONI; LAKATOS, 2007, p. 64).

No mais, embora haja posicionamento, sobretudo pelos pesquisadores mais formalistas, de que apenas o método dedutivo seja capaz de "[...] estabelecer um raciocínio efetivamente lógico [...]" (MEZZAROBA; MONTEIRO, 2004, p. 66), várias também são as objeções e críticas ao modelo.

Em que pese serem diversos e, usualmente, complexos pela necessária abstração nas considerações, os principais questionamentos dizem respeito à essencial tautologia de muitos dos raciocínios dedutivos e ao problema da seleção das premissas iniciais: o risco de serem tomados como verdadeiros enunciados que não necessariamente o são ou a própria adoção prévia de verdades absolutas que não podem ser colocadas em dúvida ao longo do estudo. Neste último ponto, críticos afirmam que a dedução "[...] assemelha-se ao [método] adotado pelos téologos, que partem de posições dogmáticas" (GIL, 2008, p. 10).

É de se considerar que talvez seja mesmo o caso de esta última crítica proceder sem que seja prejudicada, porém, a aplicabilidade do método. Já que nas pesquisas formais, e em diversas áreas do conhecimento, o autor de certa obra precisa filiar-se a uma teoria de base, "[...] para, à sua luz, proceder ao exame do fenômeno que é o seu objeto de pesquisa" (MEZZAROBA; MONTEIRO, 2004, p. 67). faz sentido (e é necessária) a filiação a certos dogmas iniciais, determinadas afirmativas que serão aceitas e defendidas pelo estudioso ao longo de sua obra.

\subsection{Método Hipotético-Dedutivo}

Conforme exposto, os métodos indutivo e dedutivo divergem em uma série de aspectos de maior relevância. Em verdade, como asseveram Marconi e Lakatos (2007, p. 71):
Quanto ao ponto de chegada, ambas as escolas estão concordes: formulação de leis ou sistemas de leis para descrever, explicar e prever a realidade. Assim a discussão versa sobre o ponto de partida e o caminho a seguir para alcançar o conhecimento.

\section{E complementam as autoras}

[...] a indução afirma que, em primeiro lugar, vem a observação dos fatos particulares e depois as hipóteses a confirmar, a dedução, como veremos no método hipotético-dedutivo, defende o aparecimento, em primeiro lugar, do problema e da conjectura, que serão testados pela observação e experimentação. Há, portanto, uma inversão de procedimentos. (MARCONI; LAKATOS, 2007, p. 71-72)

É justamente de críticas ao método indutivo que surgirá o hipotético-dedutivo. O principal expoente de tais apontamentos negativos à indução foi, na visão de muitos, Karl Popper. Esse pensador criticou radicalmente a indução, método hegemônico nas investigações científicas, até sua época, afirmando, segundo Mezzaroba e Monteiro (2004, p. 69), que:

[...] a Ciência não é capaz de atingir a essência da verdade, mas tão-somente da probabilidade. Isso quer dizer que uma teoria científica pode fornecer apenas soluções temporárias para os problemas que enfrenta, pois assim que uma eventual nova teoria responder de forma diferente, ou melhor, ao problema suscitado, a primeira restará refutada.

Mezzaroba e Monteiro (2004, p. 69) seguem iluminando o entendimeto sobre Popper e, por meio de sua explicação, conectam a presente exposição à citação anterior de Marconi e Lakatos:

[Para Popper] As teorias científicas se apresentariam como conjuntos de enunciados hipotéticos sobre determinados problemas. O que equivale a dizer que seriam apenas conjecturas. Essas hipóteses (conjecturas) formuladas por ela consistiriam em respostas provisórias diante dos quadros problemáticos aos quais se dedicam.

Nesse contexto, uma teoria pode ser dita "consistente" após sua submissão a um "[...] rigoroso processo de falseamento, isto é, à verificação empírica das hipóteses de modo a corroborá-las ou refutá-las" 
(MEZZAROBA; MONTEIRO, 2004, p. 69-70). Cabe sempre a ressalva de que a teoria mesmo aprovada por esse procedimento assume apenas condição de "provisoriedade", ou seja, é uma teoria cientificamente válida, mas apenas até que seja "refutada ou superada por outra" (MEZZAROBA; MONTEIRO, 2004, p. 69-70).

Aprofundar-se no procedimento hipotético-dedutivo demandaria desvio de rota deste breve escrito. Só a etapa de falseamento - em que muito da metodologia em tela se fundamenta - merece um sem número de estudos próprios. Assim, sendo, não será mais longa a exposição deste tópico, que se encerra com breve resumo daquilo que é mais essencial ao modelo.

O método hipotético-dedutivo tem em comum com o dedutivo "o procedimento racional que transita do geral para o particular" e, com o indutivo, "o procedimento exprimental como sua condição fundante.". $\mathrm{O}$ pesquisador seleciona uma teoria de base ou elementos teóricos para marcar seu ponto de partida, partindo destes formula hipóteses que serão verificadas "no transcorrer de sua atividade indagativa" (MEZZAROBA; MONTEIRO, 2004, p. 68).

No mais, Popper ao criticar a indução, o faz entre outros argumentos - com foco em sua não justificação uma vez que "[...] salto indutivo de 'alguns' para 'todos' exigiria que a observação de fatos isolados atingisse o infinito, o que nunca poderia ocorrer" (GIL, 2008, p. 12).

Do argumento anterior que surge a demanda pelos procedimentos de falseamento e a tomada de posição, por Popper, de inexistência de teoria verdadeira, inquestionável, insuperável e imutável.

Diante de todo o exposto, Gil (2008, p. 12) sumariza o que importa sobre o falseamento quando diz que "Enquanto no método dedutivo procura-se a todo custo confirmar a hipótese, no método hipotético-dedutivo, ao contrário, procuram-se evidências empíricas para derrubá-la".

E o autor segue em outro longo trecho que parece ser de necessária transcrição:

Quando não se consegue demonstrar qualquer caso concreto capaz de falsear a hipótese, tem-se a sua corroboração, que não excede o nível do provisório. De acordo com Popper, a hipótese mostra-se válida, pois superou todos os testesm mas não definitivamente confirmada, já que a qualquer momento poderá surgir um fato que a invalide. (GIL, 2008, p. 13)
Finalmente, sobre a aplicabilidade do método, são sólidas e imparafrasiáveis as assertivas de Gil (2008, p. 13)

O método hipotético-dedutivo goza de notável aceitação, sobretudo no campo das ciências naturais. Nos círculos neopositivistas chega mesmo a ser considerado como o único método rigorosamente lógico. Nas ciências sociais, entretanto, a utilização desse método mostra-se bastante crítica, pois nem sempre podem ser deduzidas consequências observadas das hipóteses. Proposições derivadas da Psicanálise ou do Materialismo Histórico, por exemplo, não apresentariam, de acordo com Popper, condições para serem falseadas.

Parece suficientemente madura a compreensão desse método para que se possa passar ao próximo e último da presente exposição do rol de métodos elencados pelos autores da área considerados para este trabalho.

\subsection{Método Dialético}

Finalmente, o último método a ser abordado na parcela de fundamentação teórica do presente artigo é o dialético.

O conceito de dialética vem de longa data. Inicialmente, na Grécia Antiga, confundia-se com o próprio conceito de diálogo (MARCONI; LAKATOS, 2007), tendo depois, ao longo do desenvolvimento da filosofia grega da Antiquidade Clássica, evoluido para algo mais, uma espécie de arte específica dentro do campo do diálogo, uma arte dialética ocupda do domínio da capacidade de argumentação $e$ contra-argumentação em tópicos "[...] cuja demonstração, típica dos raciocínios analítocs, não é possivel” (MEZZAROBA; MONTEIRO, 2004, p. 71).

Percebe-se então, de início, que a dialética, como método, opera, portanto, não no campo das evidências, masno campo do opinável, e, aqui, opiniões poderão ser tomadas como racionais quando forem devidamente fundamentadas e sustentadas por uma argumentação sólida (MEZZAROBA; MONTEIRO, 2004).

A arte tão desenvolvida e fundamental para a ascensão da civilização grega permaneceu em segundo plano, no entanto, durante boa parte da história subsequente, sendo "resgatada" em forma mais próxima do entendimento atual por Montaigne no Século XVI, 
Diderot no XVIII e, finalmente, por Hegel no século XIX (MARCONI; LAKATOS, 2007; MEZZAROBA; MONTEIRO, 2004).

É com este último pensador alemão que a dialética passa a ganhar, novamente, um espaço mais amplo em campos ligados à filosofia, influenciando uma série de pensadores que seguiram deste ponto em diante (MEZZAROBA; MONTEIRO, 2004).

Justamente por tamanha influência, importante compreender a visão hegeliana deste método. Sua concepção é a de que "[...] a lógica e a história da humanidade seguem uma trajetória dialética, nas quais as contradições se transcendem, mas dão origem a novas contradições que passaram a requerer solução" (GIL, 2008, p. 13).

Hegel haveria compreendido que "[...] no universo, nada está isolado, tudo é movimento e mudança, tudo depende de tudo; assim, retorna à dialética [...]" e fundamentando-se nas contradições, procura "[...] as relações das partes formadoras de um todo orgânico, busca a plenitude; ora, a contradição está presente em toda a realidade: tudo tem relação com o todo, que encerra em si próprio contradições" (MARCONI; LAKATOS, 2007, p. 82).

Dessa forma, em suma, a dialética hegeliana "[...] é um sistema, uma construção lógica, racional, coerente que pretende aprender o real em sua totalidade [...]" e para isso compreende os contrários como "verso e anverso de uma mesma realidade"; percebe que esses opostos "[...] ao mesmo tempo em que se antagonizam, também se identificam" (MARCONI; LAKATOS, 2007, p. 82).

Em outras palavras, e aqui chegando mais próximo aos conceitos operacionais do método, Marconi e Lakatos (2007, p. 82) sintetizam ao dizer que "A tese, ser, e a antítese, nada, não passam, pois, de abstrações ou momentos de um processo em que ambos são absorvidos ou superados na e pela síntese".

No que tange à aplicação do método, "[...] o objeto dialeticamente tratado é proposto, para, a seguir se auto-superar mediante o confronto com seu próprio contraditório, vindo a ser inteiramente outro como resultado de si mesmo" (MEZZAROBA; MONTEIRO, 2004, p. 73).

Enfim, trata-se de um procedimento complexo, contínuo e dinâmico por natureza, através do qual, como dito, teses e antíteses alternam-se na formação de sínteses que, em momento imediatamente seguinte perdem o "prefixo" de simultaneidade ou companhia para voltarem à condição anterior embora em situação distinta.

Não é preciso muito para perceber que há uma clara distinção da lógica positivista, que é "quebrada" para que se possa perceber a realidade através de toda uma outra concepção. O método vem sendo utilizado amplamene, sobretudo por autores ditos "críticos" ou que pretendem analisar os fenômenos no ambiente complexo em que se dão sem ignorar as influências deste naqueles.

\section{Metodologia da Pesquisa}

Vista a importância da aplicação de métodos adequados para que determinada produção intelectual possa se pretender acadêmica ou dotada de caráter científico e detalhados, ou caracterizados, alguns desses métodos científicos, ou seja, formas de condução mais rigorosa de uma exposição de ideias, passa-se à pesquisa realizada justamente a partir da percepção da relevância de tal componente metodológica em trabalhos acadêmicos.

Dessa forma, a preocupação deste estudo e, portanto, seu objetivo, é - após a breve exposição teórica - analisar a declaração, pelos autores, de utilização de uma das metodologias científicas listadas nas dissertações de mestrado de um Programa de Pós-Graduação em Administração entre os anos de 2010 e 2014. Pela delimitação temporal tem-se, segundo a metodologia, um estudo de perspectiva transversal, justamente por realizar um recorte específico na linha do tempo e analisá-lo pormenorizadamente.

Materialmente, a pesquisa foi feita filtrando-se os arquivos digitais de cada uma das 65 dissertações tomadas como objeto em busca de referências aos métodos científicos e suas nomenclaturas variáveis. Quando a ferramente não retornava resultados, procedeu-se na leitura do tópico reservado à metodologia em busca das informações. Formalmente, por sua natureza, o estudo encontra amparo em taxonomia metodológica de alguns teóricos da matéria, como se vê:

No tocante à classificação da pesquisa, tem-se que, quantos aos fins, trata-se de um estudo descritivo já que ocupar-se-á de expor características de uma população selecionada sem o "[...] compromisso de 
explicar os fenômenos que descreve, embora sirva de base para tal explicação" (VERGARA, 2013, p. 42).

Quanto aos meios, a pesquisa enquadra-se como um "estudo de caso", pois, conforme leciona Gil (1991, p. 59), esse esquema:

Também se aplica com pertinência nas situações em que o objeto de estudo já é suficientemente conhecido a ponto de ser enquadrado em determinado tipo ideal. Por exemplo, se as informações disponíveis fossem suficientes para afirmar que existem três tipos diferentes de comunidades de base e houvesse o interesse em classificar uma comunidade específica em algum desses tipos, então o estudo de caso seria o delineamento mais adequado.

Justamente estas são as intenções deste estudo: investigar à qual método dos quatro expostos na seção anterior as Dissertações do Programa analisado, defendidas entre 2010 e 2014, declaram se filiar. Em outras palavras, e parafraseando o excerto anterior, em qual daqueles "tipos" os trabalhos se enquadram, de que forma se classificam diante de tal critério.

A população do estudo, acima delimitada, foi selecionada pelo autor por representar a totalidade dos possíveis "participantes" de tal análise. Trata-se de critério próprio do autor, portanto, encontrando sustentação no conceito de amostragem dita não probabilística por Gil (2008). Vergara (2013) acrecentaria ainda que a opção de amosta frente ao universo foi realizada por tipicidade já que os elementos são selecionados por sua representatividade, que aqui é total, frente à população-alvo.

Por fim, e ainda no campo metodológico, o presente estudo serviu-se das concepções de pesquisa "quali-quantitativa" por reunir características comuns e transitar entre traços dos métodos qualitativo e quantitativo (MARCONI; LAKATOS, 2007) e fez uso do método dedutivo - sobre o qual não haverá aprofundamento nesta altura do texto, pois verdadeiramente exaurido o tema em seção anterior - estabelecendo inicialmente, como prega a doutrina, os argumentos considerados verdadeiros, quais sejam, os métodos científicos e suas características para, então, buscar conclusões formais da análise do conteúdo dos documentos tomados como objeto de estudo (GIL, 2008; MEZZAROBA; MONTEIRO, 2004).

\section{Apresentação e Análise de Dados}

Para o ano de 2014, o repositório de dissertações do sítio eletrônico do Programa de Pós-graduação pesquisado apresenta 21 obras finalizadas, defendidas e, portanto, publicizadas. Deste total de dissertações depositadas, três declaram filiar-se ao método indutivo (14,28\%); duas ao esquema dedutivo (9,52\%); e as 16 restantes não realizam opção metodológica no que diz respeito a esta componente $(76,19 \%)$.

Analisando-se o ano de 2013, são 29 as dissertações disponibilizadas no repositório institucional. Nesse contexto, 11 declaram-se de linha indutiva (37,93\%); duas, de método dedutivo (6,90\%); e 16 não apresentam informações nesse sentido, não assumindo compromisso com um dos formatos metodológicos (55,17\%).

No ano de 2012, são 15 as obras disponibilizadas pelo programa. Aqui, cinco autores apresentam suas dissertações como "filiadas" à escola indutiva (33,33\%); uma opta pelo método dedutivo $(6,67 \%)$; e nove não fazem declaração a respeito desta componente metodológica (60\%).

O cenário geral da produção do programa, nestes quatro primeiros anos de atividade, é de 65 dissertações tornadas públicas no repositório institucional e indexadas ao sítio eletrônico do Programa². Do total, 19 afirmam utilizar, como guia de raciocínio, a metodologia indutiva (29,23\%); 5 declaram optar pela dedução como forma de raciocínio aplicada à produção científica (7,69\%); e 41 não explicitam a opção ou utilização de nenhuma das metodologias ao longo de todo o corpo textual $(63,08 \%)$.

\section{Conclusão}

Realizada a pesquisa e vistos seus resultados, percebem-se números que podem ser encarados com alguma preocupação. É que de todos os textos aprovados pelo Programa de Pós-graduação estudado, a maioria não faz clara opção metodológica quanto à "técnica de raciocínio" aplicada na exposição.

2 Reiterando a intenção de não identificar o Programa de Pós-graduação em comento, as dissertações analisadas não constarão nas referências deste artigo, justamente para que sejam resguardados seus autores, orientadores e referentes produções. Dessa forma, ficam documentados apenas os números encontrados da análise dos documentos. 
Essa falta de rigor no guiar do raciocínio ao longo da produção acadêmica coloca em dúvida, segundo a definição e o alerta de alguns autores, o próprio caráter científico dos textos produzidos, uma vez que ignorada ou deixada em segundo plano a componente metodológica de maior relevância para que se compreendam as premissas do autor, o caminho de seu pensamento $e$, em última instância, a verdade ou plausibilidade de suas conclusões.

No mais, os dados, quando analisados por ano, demonstram não ser esse um ponto de maior preocupação dos autores e seus orientadores e do Programa, já que não parece haver acompanhamento dos números ligados ao "problema" e uma efetiva busca pela melhoria do indicador de "não escolha metodológica", que começa em determinado patamar no ano de 2012, apresenta ligeira melhora em 2013 e grande regresso em 2014.

Ainda, se porventura, as escolhas de métodos tenham sido feitas, mas não explicitadas ao longo da dissertação, prejudicaram o presente estudo como também o fizeram com os eventuais leitores das dissertações que precisaram intuir - quando possível - o caminho metodológico realizado pelo autor, a forma pela qual "modulou" seu raciocínio.

O rigor metodológico, no que diz respeito à opção por uma das escolas metodológicas e, portanto, à "obediência" de seus pressupostos, parece merecer maior cuidado de mestrandos e de seus orientadores para que o corpo de produção dos egressos do Programa de Pós-graduação em tela consolide-se como dotado não apenas de relevância, aplicação prática ou outros requisitos, mas também como portador de sólidas bases e caráter científico.

\section{REFERÊNCIAS}

CERVO, Amado Luiz; BERVIAN, Pedro Alcino; SILVA, Roberto da. Metodologia cientifica. 6. ed. São Paulo: Pearson Prentice Hall, 2007. 162 p.

GIL, Antonio Carlos. Como elaborar projetos de

pesquisa. 3. ed. São Paulo: Atlas, 1991. 159 p.

GIL, Antonio Carlos. Métodos e técnicas de pesquisa

social. 6. ed. São Paulo: Atlas, 2008. XVI, 200 p.
LAKATOS, Eva Maria; MARCONI, Marina de Andrade. Metodologia científica: ciência e conhecimento científico, métodos científicos, teoria, hipóteses e variáveis. 5. ed. rev. e ampl. São Paulo: Atlas, 2007. $312 \mathrm{p}$.

VERGARA, Sylvia Constant. Projetos e relatórios de pesquisa em administração. 14. ed. São Paulo: Atlas, 2013. $94 \mathrm{p}$. 